\title{
Concern raised over control of cost-benefit research in United States
}

Published at www.cmaj.ca on Dec. 18, 2009

$\mathrm{T}$ he fate of health care comparative effectiveness research in the United States may be compromised in the ongoing congressional battle over health reform.

The House of Representatives and Senate have both indicated that they're willing to plow large chunks of cash into comparative effectiveness research - a key area of medical science in which competing therapies are submitted to cost-benefit analyses.

But while the House has passed its health reform legislation, the Senate continues to horse-trade provisions (CMAJ 2009. DOI:10.1503/cmaj.109-3132) as the majority Democrats struggle to muster the requisite 60 votes needed to pass the bill before Christmas.

Should the Senate pass the health reform legislation, its version will have to go through a "reconciliation" process with the House version. Historically, finding common ground between the two arms of Congress has often involved a measure of bartering of conflicting elements, and provisions have been known to be sacrificed in the interests of saving a piece of legislation.

Although observers do not expect that the comparative effectiveness research provisions will be tossed, some analysts, such as Harry Selker, executive director of the Institute for Clinical Research and Health Policy Studies at Tufts Medical Center in Boston, Massachusetts, fret that private interests will gain control of the research agenda.

"Funds are not an issue" in the fight over comparative effectiveness research, but control has become a key concern, Selker says. As currently crafted, the Senate bill could open the door to placing substantial control over comparative effectiveness research in commercial hands, which "goes against the tradition

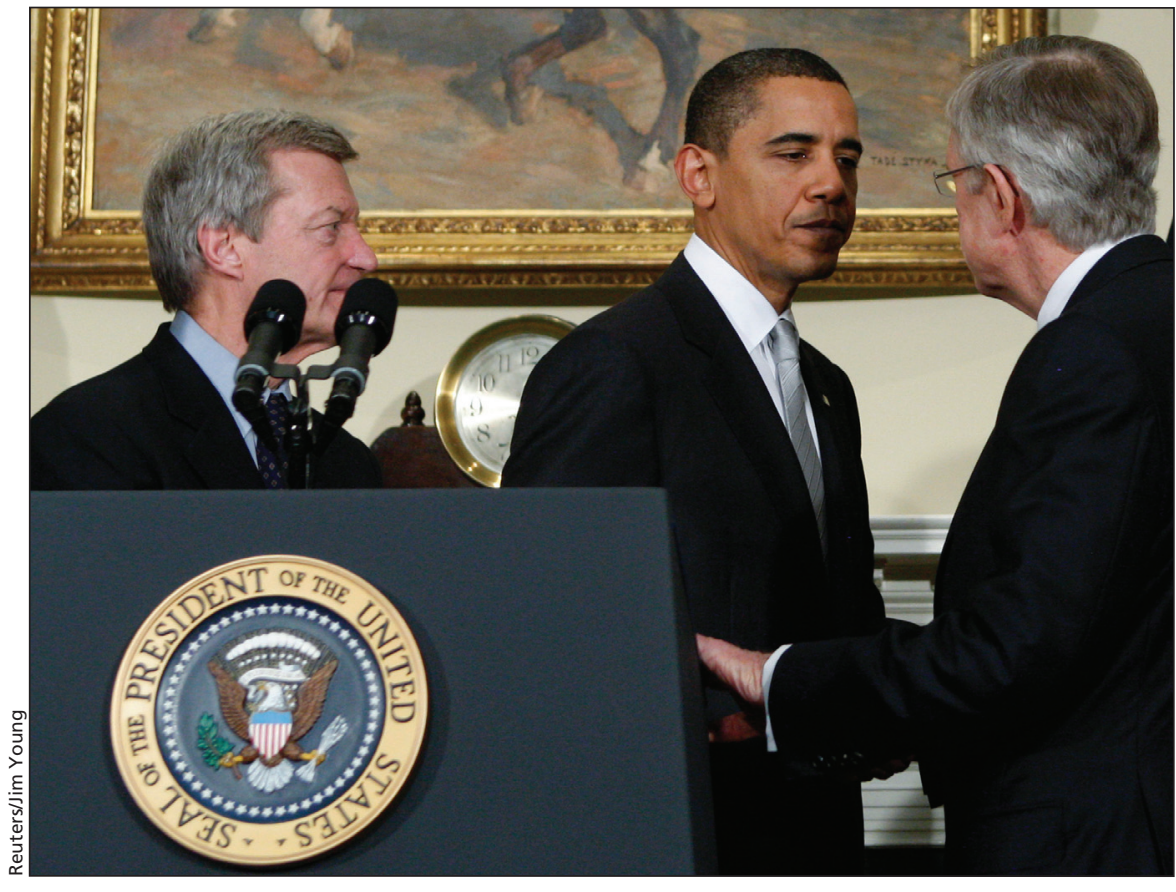

US President Barack Obama meets with Senate Majority Leader Harry Reid and Senator Max Baucus after meeting with Democratic senators at the White House in Washington, D.C. on Dec. 15, 2009.

of noninterference from commercial interests at the NIH [National Institutes of Health] and elsewhere in American science."

Both the House and Senate versions of health reform legislation propose to expand comparative effectiveness research. The House would establish a "Comparative Effectiveness Research Trust Fund" that would create and finance a "Comparative Effectiveness Research Commission," while the Senate would establish a "Patient-Centred Outcomes Research Trust Fund" that would fund a "Patient-Centred Outcomes Research Institute." Each of the bills would allocate roughly US\$600 million to the cause, Selker estimates.

That would build on considerable support that Congress has already provided to the area. As part of earlier economic stimulus legislation, US $\$ 1.1$ billion over 10 years was allocated for health care research and quality, including US $\$ 400$ million for the US National Institutes of Health to create an agency for health care research and quality and a federal coordinating council on comparative effectiveness research and commission an Institute of Medicine study on priorities for cost-benefit research.

In late June 2009, the Institute of Medicine released a report listing 100 such priorities, in 29 research areas (www.iom.edu/Reports/2009/Comparative EffectivenessResearchPriorities.aspx).

In its report, the highly respected health arm of the US National Academy of Sciences endorsed "a balanced portfolio of research topics that, collectively, address broad societal needs." Among the high-priority topics identified were interventions such as disease prevention, systems of care, drug therapies, devices, surgery and monitoring 
of disease. Comparing treatment strategies for atrial fibrillation, hearing loss, primary prevention, inflammatory diseases and antibiotic resistance were among the top 10 priorities listed.

Selker says a new era for US health systems research could be at hand. "Comparative effectiveness research, which was formerly only of interest to clinical and health services researchers, is now in the public arena," he explains. "This should have a direct positive influence on health. It may also have a positive impact on cost effectiveness. Reliable, well-accepted information on treatment effectiveness on which to base payment decisions would be very helpful."

But the push to expand such research has not gone unchallenged by segments of the health industry which fear the commercial consequences for treatments found to be uncompetitive or less effective.

Medical device and pharmaceutical manufacturers lobbied against the inclusion of comparative effectiveness research in the economic stimulus bill and were active in the introduction of a Senate bill which would have prohibited the federal Medicare and Medicaid programs from using comparative effectiveness research to "deny coverage."

Selker worries the Senate bill could force health agencies to cede "substantial influence to the medical products industries." The bill proposes a new private-public research entity which, "owing to industry lobbying," guarantees industry three of 15 board seats, he says. Employing this approach to administering comparative effectiveness research funds would contrast with practices at the National Institutes of Health and the Agency for Healthcare Research and Quality, "which have strict conflict-of-interest rules to ensure that science is free of inappropriate commercial influence." Selker also challenges "language requested by industry lobbyists" that threatens to withdraw federal funding from researchers who fail to satisfy requirements that research boards include commercial representatives.

The outcome is being closely watched by some Canadian observors, including Irfan Dhalla, a specialist in health care governance at the University of Toronto in Ontario.

While the push to expand comparative effectiveness research in the US is a "step in the right direction that we in Canada need to follow," the American "process has become highly politicized," he says. "If the studies are publicly funded, why would the government cede decisions about governance and peer review to a joint academia-industry committee?"

Comparative effectiveness research, he adds, "should be held to the same high standard as other publicly funded research." - Paul Christopher Webster, Toronto, Ont.

DOI:10.1503/cmaj.109-3140 